\title{
Research on the Current Situation, Problems and Countermeasures of Mental Health Education for Postgraduates in China's Four Medical Universities
}

\author{
Sun Lei, Chen Duanying*, Xue Junfeng \\ Department of Humanities and Social Sciences, Hubei University of Medicine, Shiyan, China \\ Email address: \\ 741093548@qq.com (Sun Lei),44711984@qq.com (Chen Duanying), wdsxuejunfeng@126.com (Xue Junfeng) \\ ${ }^{*}$ Corresponding author
}

To cite this article:

Sun Lei, Chen Duanying, Xue Junfeng. Research on the Current Situation, Problems and Countermeasures of Mental Health Education for Postgraduates in China's Four Medical Universities. International Journal of Law and Society. Vol. 1, No. 3, 2018, pp. $102-107$. doi: $10.11648 /$ j.ijls.20180103.11

Received: July 18, 2018; Accepted: September 3, 2018; Published: September 30, 2018

\begin{abstract}
The mental health of medical postgraduates is not only related to personal development, but also related to the future of China's health system. The purpose of study is to analyze the necessity of the mental health education for medical graduates and the existing problems as well as to probe the effective methods of the mental health education of medical postgraduate. Questionnaire is implemented among students in four medical universities in Hubei and Hunan Provinces. The result concludes the problems of medical students' mental health education, such as insufficient emphasis, medicalization, singularity and poor relevance. The study argues that it is necessary to explore the effective ways of mental health education for medical graduates in the following aspects: (1) to raise awareness and to enhance the awareness of mental health education of medical postgraduates; (2) to scientifically locate and clarify the relationship between mental health education and medical education; (3) to integrate resources to build medical student's mental health education system; (4) to build a platform to expand the medical graduate students mental health education channels.
\end{abstract}

Keywords: Medical Postgraduate, Mental Health Education, Channel

\section{Introduction}

Recent years have witnessed the increasingly expanded enrollment of graduates in China, which greatly challenges the management of graduate students' education. The postgraduates in medical school are faced with heavy studying tasks and extended learning process, which leads to more or less serious mental health problems among them. Therefore, many researches on mental health education for medical postgraduates have been undertaken. This research ranges from the questions of what causes their mental health to what pedagogical and administrative methods may be suggested for medical postgraduates' mental health education. Such research centers on the single or multiple aspects of mental health education. The majority of the research on mental health education for medical postgraduates remains at the levels of internal and external causes, representations, macroscopic and microscopic solutions, especially the research on probing into the interference factors that lead to mental crisis which primarily results in their age and the surroundings such as bad environmental adaptation, academic and employment pressure and anxiety and depression caused by interpersonal relationship [1], the interplay and contradiction between mental health and job burnout [2], gender difference [3], personality [4-6], personality of neuroticism and psychoticism [7-8], family factor [9-10]. However, the research on the trans-regional and trans-campus comparison of mental health problems and corresponding solutions is minimal. The specialty of the medical majors and the professional responsibilities of healing the wounded and rescuing the dying require medical graduate students of good ability of adjusting mental as well as the capability of comprehensively grasping the relationship between the patients' mental health and diseases and disorders. In this 
sense, it is worthy of carrying the research on the improvement of medical graduates' mental health education.

Based on the results of questionnaires conducted among the medical students in Hubei and Hunan Province, this paper is to analyze the necessity of the mental health education for medical graduates and the existing problems as well as to probe the effective methods of the mental health education of medical postgraduate. Also, it attempts to probe the effective methods of the mental health education of medical postgraduate. Questionnaire is implemented among students in four medical universities in Hubei and Hunan Provinces. The emergent mental problems afflicting medical postgraduates and accompanying suggested countermeasures are to be discussed.

\section{The Necessity of Mental Health Education for Medical Postgraduates}

\subsection{Mental Health Education Is Part of Medical Postgraduates' Comprehensive Quality}

Mental health education can improve the mental quality and humanistic quality from aspects of knowledge, mind and skill. To begin with, mental health education can spread knowledge of mental health. The implementation of psychological courses and lectures in the educational practice of mental health among medical postgraduates can allow students to comprehensively and extensively acknowledge the characteristics and tendency of stages of psychological development. When puzzled, they can attend calmly instead of following the crowd blindly or breeding unfounded suspicion. Secondly, mental health education can cultivate and maintain sense of mental health. Mental health education among medical postgraduates can help them build scientific sense of health, fully acknowledge the important role that mental health plays in comprehensively improving their qualities and releasing potential abilities. Moreover, postgraduates can develop sense of self-help, preference for assistance and offering help so that they can safeguard and strengthen self-mental health unconsciously. Thirdly, mental health education can help postgraduates to improve mental health maintain skill. The mental health education of medical postgraduates focuses on the case analysis and discussions on student environmental change and adjustment, ambiguity and confusion of self-consciousness, school-work problems, interpersonal interaction dilemma, love and sexual psychology, emotion, internet psychology. Psychological game experiences and other forms of activities are also conducted to train coping strategies and develop mental health maintenance skills.

\subsection{Mental Health Education is Important Guarantee of Ideological and Political Education for Medical Postgraduates}

It seems that ideological and political education is not related to mental health, yet originally there is something common between them. Both ideology and politics and mental health belong to the category of ideologia. Besides, they contain common elements such as ideal, faith, morality and volition. [11] They cannot be separated completely. Good ideological quality is the core of good psychological quality. Ideological and political education consists of the education of world view, life view, and value, ideal, morality and faith. It is also the core of psychological structure. Therefore, it is of great importance to view the mental health education as a complimentary education of ideological and political education among medical postgraduates. As the deepening of Chinese comprehensive reform, many social problems emerge and grow; varied mental problems among different populations ensue, medical postgraduates are not excluded. As they are living in "ivory tower" for a long time, compared with the social peers, some medical postgraduates' mind is less mature with low psychological endurance and more inclination to go extremes in thoughts. In this case, mental counselling are suggested to be carried out among these students based on the personal traits to make the best of the situations. In this way, they are guided to adjust the behaviors. By doing the half work, one will the get the double result in mental health education. Thus it can be seen, mental health education should be the important guarantee of medical postgraduates' ideological and political education in New Times.

\subsection{Mental Health Education Is an Inevitable Requirement of Medical Postgraduates Adapting Themselves to the Modern Medical Mode Transformation.}

With the development and progress of medical practice, medical guiding ideology has transformed from bi-medical model to biology-psychology-social medical mode. The new medical mode proposes that human body is not only influenced by biological factors and others, but influenced by psychological factors. Consequently, the public has changed their medical ideas of diseases, health and disease prevention. The modern medical mode transformation requires of the implementation of mental health education for medical post-graduates. Therefore, it can help students to untangle the dialectical relationship between biology, psychology and social medical mode and to grasp the idea that human's psychologically social factors can manipulate individual physiological functions and health condition, apply itself fully in the series of medical research and services like clinical diagnose, treatment, rehabilitation, and disease prevention and healthcare. In order to meet the training requirements above, it is suggested to strengthen the psychological education for medical post-graduates to adjust them to the medical mode transformation.

\section{The Current Condition and Existing Problems in the Present Psychological Education for Medical Postgraduates}

It is extremely necessary to implement psychological education for medical post-graduates. However, there is a 
precondition to implement effective psychological education, that is: it is suggested to conduct an investigation and survey of the present education condition and post-graduates' need of psychological education. Based on the result analysis of the random questionnaire among medical post-graduates in four medical universities in two provinces, this paper concludes the following problems of the present psychological health education.

\subsection{No Enough Emphasis Is Put on the Mental Health Education}

The National Ministry of Education expresses provision in formal files to strengthen psychological education in university all over the country. Most of the medical universities and colleges have successively set up institutions to conduct mental health education. However, there is a lack of necessary mental health education for post-graduates compared with that for undergraduates; yet, not much efforts have been put in. [12] On one hand, there might be cognition deviation of mental health education among the institutions which deem that highly educated people are the outstanding persons in social group and are necessarily equipped with fine psychological qualities. Yet the actual data shows that it should not be too optimistic about the post-graduates' psychological condition. [13-15] The research finds out that: $75.6 \%$ of the participants self-reports they have psychological distress from academic studying (48.9\%), employment problems $(31.1 \%)$, relationship problems with mentors $(22 \%)$, emotional problems $(17.8 \%)$ and interpersonal relationship problems (11.1\%). On the other hand, medical post-graduates might neglect their own mental health. They think they should put their time and energy in studying, scientific research. Mental health problems only happen to certain persons. $15.2 \%$ of the participants in the survey regard it unnecessary to specifically implement mental health education for medical post-graduates. The neglect and contempt of the mental health education for medical post-graduates is the source that leads to other problems.

\subsection{Education in Medical Universities are Inclined to Medicalization}

There is a cognition deviation of medicalization of health concept in the mental health education for medical postgraduates. Many people confound psychological problems with abnormal psychology, taking a one-sided view of idea that people with psychological problems have psychosis. While medical students have learnt such courses as medical psychology and psychiatry, they do not have to learn courses of mental health, which might increase their academic burden. According to the survey, $46.7 \%$ of the participants think, "those who acquire knowledge of psychiatry are able to maintain personal mental health". Obviously, this viewpoint is biased. On one hand, this kind of cognitive deviation leads to the fact that some students mistakenly argue only those with severe symptoms of psychiatry are afflicted with mental diseases, which make themselves indifferent to some mental problems and phenomena. Compared with people from other occupations, they are more reluctant to admit their affliction of mental diseases. Consequently, their condition of mental health deteriorates and slips into tragedy which can be avoided; on the other hand, the cognitive deviation can cause the "patients" more inclined to resort to psychological diagnosis and psychological treatment instead of psychological consultation and assistance. [16]

\subsection{Education of Mental Health Confronts Developmental Isolation and Simplification}

The mental health education is a systematic engineering. It demands for collaboration of all sectors of the school, inter-coordination of all kinds of subjects and comprehensive penetration of classroom teaching. However, there is a tendency towards isolation and simplification in actual teaching implementation. It is primarily presented as the following: firstly, Psychological Consultation Center is all by itself, barely having contact and communication with other educational sectors. Moreover, it is hard of it to get support from other sectors and teachers of the school; secondly, mental health education is independent from ideology and politics education. These two do not collaborate with each other; thirdly, mental health education for postgraduates is carried out solely with simple methods. There is lack of organic fusion of mental health education and postgraduates' daily life and learning. It does not efficiently use or integrate education resources to manage a harmony environment in teaching; fourthly, mental health education for postgraduates does not take advantage of mentors, peers, even postgraduates' self-initiatives. The survey on the working forms of mental health education carried by HBMU shows that $80 \%$ of the participants turn to Psychological Consultation Center, for example promotion of mental health knowledge (51.1\%), group mental consultation $(37.8 \%)$, mental health education courses $(33.3 \%)$, and individual mental consultation (24.4\%). While there are only $8.9 \%$ of the participants turning to their mentors, $6.7 \%$ to school counsellor or the Head teacher. The results show that there is relatively great differences between working forms of mental health education carried by the school and the working form students want. $29.8 \%$ of the participants want to get help from their mentors when feeling great pressure, while $17.1 \%$ of the participants wish to get help from the school counsellor or the Head teacher.

\subsection{The Mental Health Education Is Lowly Targeted}

The mental health education for postgraduates have not received full attention from the whole society. The exploration from the theoretical and practical aspect have much imperfection. The mental health education intended for postgraduates share in common with that for undergraduates in contents, methods and means in mental health education. So far, there is no full-stack, independent mental health education system for postgraduates. Moreover, there has not been education theory and methods that fit well with postgraduates' 
mental characteristics. [17] As postgraduates have quite different mental characteristics from undergraduates, the present research on mental health education for postgraduates is not ideal. Besides, as a special group, medical postgraduates confronts different pressures from those of other majors. [18] According to the survey (in which there are multiple choices), $48.9 \%$ of the participants argue that they feel pressure of the academic learning, $31.1 \%$ of the employment, $22 \%$ of the relationship with their mentors. The primary stressors that affect postgraduates' mental health level are daily in-class study, clinical training and internship. [19] Other factors such as interpersonal pressure $(17.8 \%)$ and emotional issues $(17.8 \%)$ that postgraduates from other majors suffer are not the primary stressors for medical postgraduates. Therefore, it is suggested that mental health education should enrich and improve teaching methods, update teaching contents to construct education system that fit well with medical postgraduates' mental characteristics based on medical postgraduates' mental characteristics.

\section{The Effective Methods of Mental Health Education for Medical Postgraduates}

\subsection{Increasing and Enhancing Awareness of Mental Health Education for Medical Postgraduates}

Medical postgraduates are the major forces driving the national medical and health services development. Their mental health not only relates to their own mental health, but also relates to the quality of students in medical education, more importantly, to the development of national medical and health services. The school faculties should fully recognize the important and urgency of the mental health education for postgraduates and set up concept of "everyone is responsible for mental health education" and run the mental health education through the postgraduate education and put it into practice. The practitioner in mental health education are suggested to learn psychology knowledge, innovate teaching contents, improve teaching method, improve ability of theoretical research and educational practice instruction in order to effectively improve the mental health level of medical postgraduates.

\subsection{Scientifically Positioning to Sort out the Relationship between Mental Health Education and Medical Education of Medical Postgraduates}

Engel, American psychiatry and physician professor, proposer of Biological-Mental-Social Medicine Mode, argues that: "in order to understand the decisive factor of disease and reach the reasonable mode of treatment and hygiene, medical mode should consider patient, the environment in which patients live and the complementary system designed by the society to defend the destructive effect of disease." Therefore, mental health education should be an important part of medical education. Firstly, more importance is supposed to be attached to mental health education courses in education for medical postgraduates. Practitioners in mental health education should help students to set up mental health conception; secondly, in courses of mental health education, medical psychology and pathergasiology, practitioners are suggested to pay attention to the concepts of healthy psychology, unhealthy psychology, normal psychology and abnormal psychology and help students to adjust cognition deviation to form good mental health view. Thirdly, in medical education practice, mental health should be emphasized to strike mental health view root in students' heart.

\subsection{Integrating Resources and Constructing Mental Health Education System for Medical Postgraduates}

Considering the particularity of medical students, mental health education system should be consisted of the following four groups: the first group are mental health education experts including full-time and part-time mental health education practitioners, who provide professional guide. The second group are teachers who are responsible for students' affairs, including deputy Communist Party Secretary, team leader of postgraduates' affair working-set, college counselors, class head teacher and administrators who are in charge of all levels of students' affairs. This group are main force of preventing and intervening mental health crisis. The third group are the mentors who play important role in discovering, solving and dealing with students' mental health crisis. The fourth group are the instructors in clinical departments. This group, together with postgraduates' mentors, navigate the way to mental health education for medical postgraduates.

\subsection{Setting up Platform and Develop Channels of Mental Health Education for Medical Postgraduates.}

Mental health education course is a stable and systematic health education system. It is also the main channel for universities to carry out mental health education for medical postgraduates. The school are suggested to efficiently take advantage of this main channel to allow students to systematically acquire mental health knowledge training, to cultivate sense of mental health, to enforce psychological adjustment ability, to promote healthy development of personality. In addition, it is suggested to develop educational channel of mental health of medical postgraduates. Firstly, internet technology should be used effectively to build the new platform of mental health education for medical postgraduates. The school should use the timeliness, efficiency, and tacitness of the internet to its advantage. By carrying out mental consultation through the internet, the school can largely promote the initiative and implementation effect of the mental health education for medical postgraduates. Secondly, it is suggested to set up peer consultant in order to realize effectiveness of health education point to surface. The features of life-oriented, mutual aid, community-based and good acceptance of peer consultant should be put into use. Meanwhile, peer consultants are suggested to be chosen in postgraduates under same mentor, or in peers in same lab or research group so as to leave no blind spot for mental health 
education for medical postgraduates.

\subsection{Emphasizing Law Education and Promoting Medical Postgraduates' Awareness of Health Law}

Enforcing medical postgraduates' awareness of health law is not only a necessity of improving their medical humanistic quality, but also the necessity of improving talent cultivation quality. British Educator Flix said, "it is inhuman to regard medicine as a technology to acquire". Compared with educational standard of World Federation for Medical Education, the law education for medical postgraduate cultivation is relatively backward and weak. Based on present situation, it is suggested to carry out reform of courses intended for medical postgraduates and change traditional teaching mode of medical majors and integrate laws and regulations into the daily education of all majors. For example, as for postgraduats from different research areas or majors, health law teachers can work together with mentors to list law books and guide students to read. Legal Medicine is added to American newest surgery textbook, which particularly emphasizes that the doctors should respect patients' rights. When providing academic guidance, mentors from different majors should pay attention to teach knowledge of law as well as medicine and ethnic. [20]

\section{Conclusion}

This study analyzes the necessity of the mental health education for medical graduates and the existing problems. It also attempts to probe the effective methods of the mental health education of medical postgraduate. The result of the questionnaire carried out among students from four medical universities in China's Hubei and Hunan Provinces shows that the mental health education for medical graduates is lack of insufficient emphasis and tends to medicalization, singularity and poor relevance. The study argues that it is necessary to explore the effective ways of mental health education for medical graduates in the following aspects: (1) to raise awareness and to enhance the awareness of mental health education of medical postgraduates; (2) to scientifically locate and clarify the relationship between mental health education and medical education; (3) to integrate resources to build medical student's mental health education system; (4) to build a platform to expand the medical graduate students mental health education channels.

\section{Acknowledgements}

This program is Supported by Hubei University of Medicine (NO. 2017QDJRW07).

\section{References}

[1] Shi, D.D. The Psychological Health Education Present Situation and Countermeasures of Medical Graduate Students [C]. Education Teaching Forum. 2017(5): 238-239.
[2] Ye, H. Y., He, H. Y., \& Chen, X. Research on the Current Situation and Solution of Mental Health and Bob Burnout of Medical Graduate Students from the Perspective of theory of traditional Chinese medicine [J]. Journal of Traditional Chinese Medicine Management. 2017, 25(20): 5-7.

[3] Shen, K., Huang, D., Liu, Q., \& Zeng, X. T. Meta-Analysis of Mental Health Status of Medical Graduate Students in 2006-2016 [J]. Journal of Henan University (Medical Science), 2017, 36(2): 85-90.

[4] Mi, Z. H., C, H. J., Li, H. M. Mental Health and Personality Characteristics of Medical Postgraduates [J]. ACTA Academic Medicine Qingdao University. 2017, 52(5): 610-612.

[5] Guo, L, Wang, P. L., Wang, H. N., et al. An Analysis of Personality Characteristics and Psychological Status of Newly-recruited Medical Postgraduates [J]. Journal of Psychiatry, 2017, 30(5): 337-339.

[6] Shen, K., Huang, D., Liu, Q., Guo, Y., Zeng, X.T. Correlation between mental health and personality Characteristics of Chinese medical students: a meta-analysis $[\mathrm{J}]$. Chinese Journal of Evidence-Based Cardiovascular Medicine. 2017, 9.

[7] Wu, C. L., Liu, X. L., You, W. J., et al. Canonical Correlation Analysis of Relationship between Personalities Characteristics and Mental Health Status among Medical Postgraduate Students [J]. Chinese Journal of Health Statistics, 2017, 34(3): 421-423.

[8] Shi, F.Y., Li, W. Canonical Correlation Analysis of Relationship between Personality Traits and Mental Health mong Medical Students [J]. Modern Preventive Medicine, 2015 42(22): 4122-4125.

[9] Chen, J. Study on Psychological Health and Family Factors in Three Medical University Students [D]. 2017.

[10] Li, S. L., Ting, Y. Alienation, Family Function and Self-esteem in Hainan Medical Student [J]. China Journal of Health Psychology. 2017, 25(8):1187-1190.

[11] Zhong, X, Y., \& Li, M. Research on the Mental Health and Personality of Fresh Postgraduates [J]. International Chinese Neuropsychiatry Medicine Journal, 2003, 4(2): 89.

[12] Sun, Y. Solutions to Problems of Mental Health Education for Postgraduates [J]. China Higher Education Research, 2006, 12(11): 38-39.

[13] He, C. M., \& Jiang, Y. Q. Mental Stress Status and Solutions Discussion of Postgraduates [J]. School Communist Party Construction and Ideology Education, 2005, 501 (3): 81-83.

[14] Xie, X. Q. Exploration of Postgraduates' Mental Health Education in Local Colleges and Universities [J]. School Communist Party Construction and Ideology Education, 2016, 528 (5): 85-86.

[15] Jiang, Y. Q. Song, M. X., \& He, C. M. Thinking of Building up Postgraduates' Mental Crisis Alert Mechanism---based on the Survey of Postgraduates' Mental Condition in Jiangxi Province [J]. School Communist Party Construction and Ideology Education, 2013, 450 (3): 79-81.

[16] Jin, M., \& Wu, L. M. Exploration of Enhancing Long-term Medical Postgraduates Mental Heal Education [J]. Medicine and Society, 2008, 21 (8): 52-53. 
[17] Xie, H. M., \& Li, Z. Q. Mistakes in Postgraduates' Mental Health Education and Solutions [J]. Journal of Dalian University of Technology (Social Sciences), 2002, 23 (4): 79-82.

[18] Zhu, P., \& Lv, L. Necessity of Enhancing Medical Postgraduates' Mental Health Education and Education Solutions [J]. Medicine and Society, 2008, 21 (8): 56-57.
[19] Chen, D. Y., Sun, L., \& Wang, etc. Research on Medical Students' Daily Life Time Pressure Index [J]. Chinese Journal of Medical Education, 2012, 32 (3): 377-380.

[20] Zhen, N., Xie, H., \& Su, J.J. Survey and Thinking of Current Situation of Medical Postgraduates' Law Awareness [J]. China Health Law, 2010, 18 (4): 35. 